\title{
Liver and Intrahepatic Bile Duct Malignant Non-Epithelial Neoplasm
}

National Cancer Institute

\section{Source}

National Cancer Institute. Liver and Intrahepatic Bile Duct Malignant Non-Epithelial

Neoplasm. NCI Thesaurus. Code C7115.

A malignant non-epithelial neoplasm that affects the liver parenchyma and intrahepatic bile ducts. Representative examples include lymphoma, angiosarcoma, and undifferentiated (embryonal) sarcoma. 